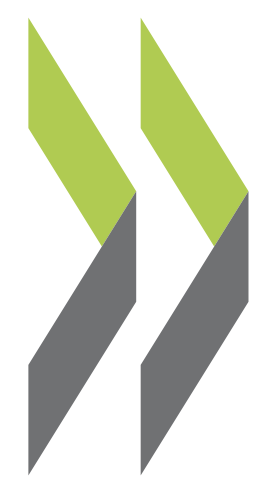

PEB Exchange, Programme on Educational Building 2007/01

Francisco Marmolejo, Reynold Gonzalez,

Higher Education Facilities: Issues and Trends

\section{Nils Gersberg,}

Suvi Nenonen,

Pablo Campos CalvoSotelo

https://dx.doi.org/10.1787/260546082436 


\section{Higher Education Facilities: Issues and Trends}

Issues that will shape the future of higher education institutions and new trends in campus architecture were the themes of a recent international seminar. Francisco Marmolejo, former consultant to the Organisation for Economic Co-operation and Development (OECD), presents here an overview of the seminar, explaining changes taking place in the area of higher education facilities and providing participants' views. Presentations from three countries are also described below: Mexico's Monterrey International Knowledge City; the higher education learning environment and the Finnish technology hub of Otaniemi; and, in Spain, the University of Salamanca's R\&D\&I Building.

\section{OVERVIEW}

By Francisco Marmolejo, University of Arizona, United States

Peter Drucker shocked many in 1997 when he suggested that "universities won't survive" and argued that "today's [college] buildings are hopelessly unsuited and totally unneeded". ${ }^{1}$ Although Drucker was perhaps exaggerating with this prediction since universities are still around and continue to grow, he helped us to recognise that while higher education is becoming a dynamic, global enterprise, the strategic management of higher education facilities is becoming increasingly complex.

Not surprisingly, in a recent study conducted among the most important management-oriented higher education associations in the United States, an increasing number of higher education leaders identify the challenges associated with "aging and expanding facilities" as one of the top change drivers in the field, exceeded only by insufficient financial resources, technological change and changing student demographics. In the same report, "insufficient facilities" are also considered among the top threats to the success of higher education. The study concludes with a call to action and the recognition that leadership is "a key ingredient that will ensure higher education's future success and help mitigate its threats." ${ }^{2}$

Two of these change drivers, resource scarcity and information technology, figure as well in the top ten critical issues that higher education facilities professionals face, according to The Association of Higher Education Facilities Officers in the United States (see table below).

There is no question that, confronted with the changing needs and means for delivering education, institutional planners and managers need to reconsider the way higher education facilities are designed, planned and managed.

1. Drucker, P. (1997), interview in Forbes, 10 March.

2. Goldstein, P.J. (2006), The Future of Higher Education: A View from CHEMA, Council of Higher Education Management Associations, Washington, DC., www.appa.org/files/pdfs/appa39a_screenopt.pdf. 


\section{Table 1. Top ten critical higher education facilities issues}

1. Resource scarcity and affordability.

2. Performance measurement and accountability.

3. Customer service.

4. Information technology.

5. Developing the laboratory and classroom of the future.
6. Facility reinvestment and total cost of ownership.

7. Workforce issues.

8. Sustainability.

9. Energy resource management.

10. Safety, security and business continuity.

Source: APPA (Association of Higher Education Facilities Officers) (2006), University Facilities Respond to the Changing Landscape of Higher Education, APPA, Washington, DC.

For this reason, higher education facilities professionals from Mexico and other countries convened at a seminar held in the city of Zacatecas, Mexico, on 29-30 May 2006. The seminar was held at the new campus of the Autonomous University of Zacatecas (UAZ), and was co-organised with the OECD in collaboration with the Mexican Ministry of Education (SEP), the Administrative Board of the Federal School Construction Programme (CAPFCE) and the Mexican Association of Universities (ANUIES).

More than 100 institutional leaders, higher education facilities professionals and representatives of government agencies, from Argentina, Canada, Greece, Finland, Mexico, Spain, the United Kingdom and the United States, met in Zacatecas to discuss the challenges outlined above and to identify and examine important trends that could influence the planning, design and management of higher education facilities.

In the particular case of Mexico, the seminar was a pioneering effort to bring together higher education representatives in the area of facilities planning and management. In a country characterised by a recent tremendous growth in its higher education infrastructure, professionals in the area have not yet developed a network to share best practices and to learn about new approaches. Some of the attendees saw the seminar as a "seed" initiative which may eventually evolve into a periodic forum and a supporting organisation.

A dialogue conducted among participants during the wrap-up session provided some insights into follow-up items that the OECD might consider for further research and dissemination. These include addressing the following needs: identifying innovative models for financing facilities' design, planning and management; adopting technology in a faster and more proactive way; further developing sound comparable performance indicators and benchmarking systems; and establishing more transparent processes and mechanisms.

All participants agreed to the need to periodically organise similar events which bring together individuals and units from universities that are usually marginalised from policy discussions, technical workshops and professional development opportunities.

To contact the author:

Francisco Marmolejo

Executive Director

Consortium for North American Higher Education Collaboration

University of Arizona

220 W. Sixth Street, Tucson, AZ 85721-0300

United States

E-mail: fmarmole@email.arizona.edu 
For further information, contact:

OECD Programme on Educational Building

2, rue André-Pascal

75775 Paris Cedex 16

Tel.: 33145249260

E-mail:peb@oecd.org

\section{MEXICO'S MONTERREY INTERNATIONAL KNOWLEDGE CITY}

By Reynold Gonzalez, Research and Technological Innovation Park, Mexico

The Governor of Nuevo Leon, Mexico, has conceived a programme to build an economy based on innovation and knowledge for Monterrey, the state's capital and the country's industrial centre. The Monterrey International Knowledge City Programme, based on an alliance between universities, companies and the government, is designed to put the population's creative talents to greater use.

The long-term vision for Knowledge City is to "increase the state's per capita gross domestic product through knowledge industries and activities and to promote a culture of innovation". Nuevo Leon aims to emulate the economic achievements of countries such as Ireland, Korea and Spain where a clear relationship has been established between economic growth and investment in research, development and innovation. The state needed a vision to provide more stable and sustainable long-term growth based not only on manufacturing but on intellectual services, or "mentefactura".

\section{Implementing the programme}

The programme's general plan consists of the following six basic strategies. Actions taken as part of the first three are described below.

1. Redesign the agenda of the Nuevo Leon education system.

2. Attract research centres and innovation and technological development companies.

3. Create new innovative companies.

4. Promote innovation in existing companies.

5. Increase the urban and cultural infrastructure.

6. Disseminate the new culture.

\section{Redesign the agenda of the Nuevo Leon education system}

Within the educational strategy, the academic agenda for secondary and higher education institutions was redesigned to emphasise five technological areas: biotechnology, health sciences, nanotechnology, mechatronics and, of course, information technology. These areas were identified by the programme as necessary to increase economic growth through innovation.

At the level of primary education, the State Ministry of Education has launched the Innovec programme. This programme promotes teaching science in a practical

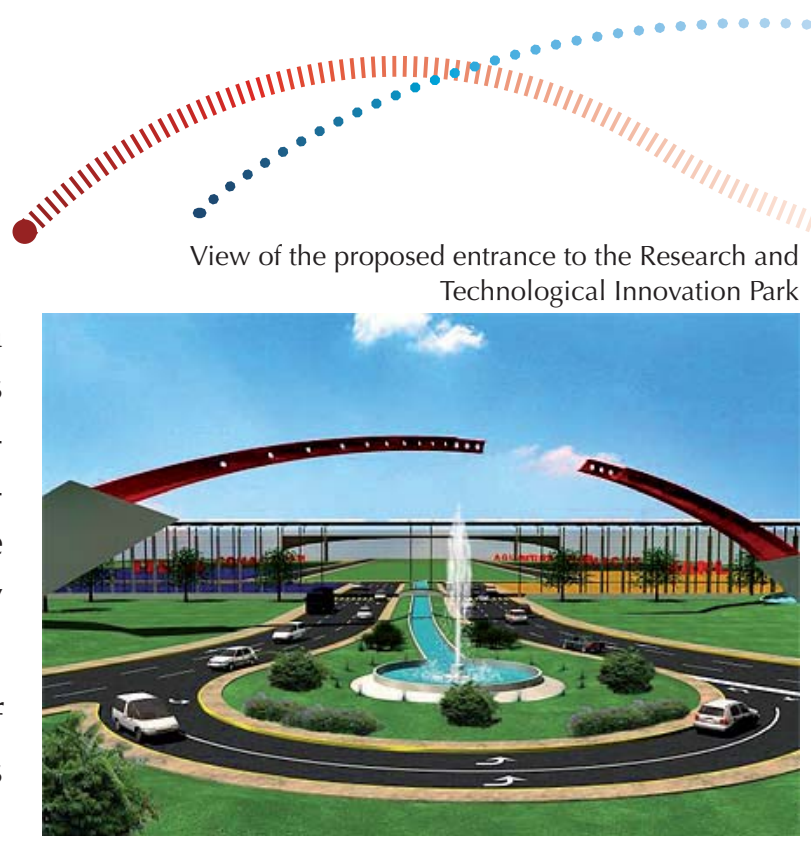



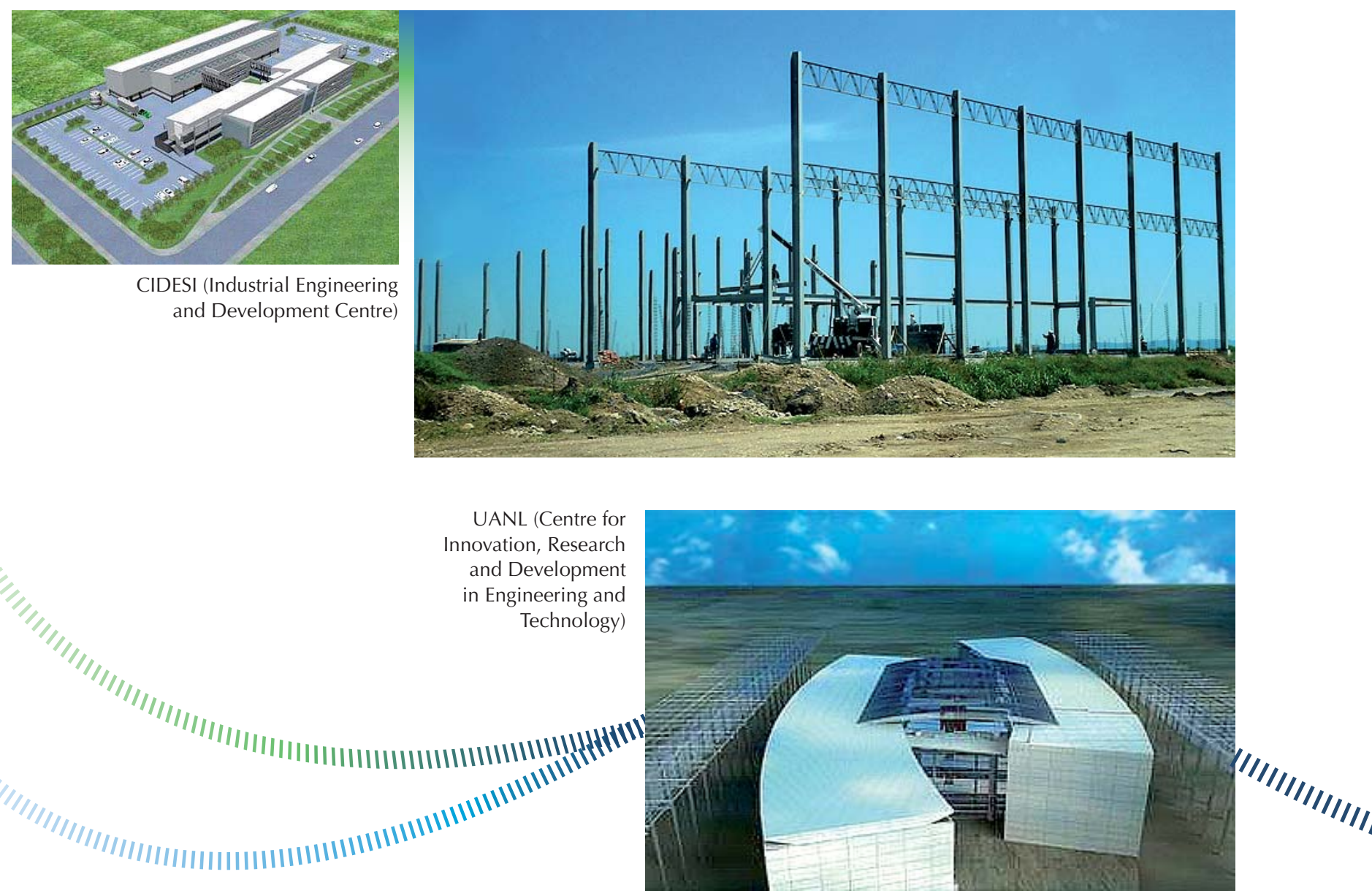

and exploratory way, to simultaneously stimulate appreciation for science and a spirit of invention in students and interest them in a career in research when the time comes.

\section{Attract research centres and innovation and technological development companies}

As part of the strategy to attract innovating centres and companies, a Research and Technological Innovation Park is under construction. The purpose of the park, located in Apodaca, is to integrate innovative research and development by linking universities, companies, and research and development centres.

The first phase of creating the park involves establishing 11 institutions: four university centres; two centres for the National Council for Science and Technology; a centre for advanced research called CINVESTAV; a cluster of 42 software development companies; a private company specialising in the research and development of radio frequency identification; a centre for water research; and a centre for furniture innovation and design.

\section{Create new innovative companies}

Since the start of the Monterrey International Knowledge City Programme in 2004, over 15 research and development centres, along with three high technology incubators and three product design centres for manufacturing companies, have been established in the metropolitan area through the efforts of collaborating universities.

The programme also promotes the installation of workshop facilities using the Russian TRIZ methodology. This methodology allows engineers to significantly enhance their inventive capacity to solve problems and helps them develop ideas that are useful and patentable. 


\title{
Conclusion
}

Monterrey will not become a knowledge city through sluggish developments, but requires disruptive changes which set new standards involving the whole community. This programme is not a real estate project, but some technological parks will be built. It is not a university campus, but the active participation of universities and their researchers is key. It is not a short-term project, but a way of life. It is not "made in Mexico", but created in Mexico.

The Monterrey International Knowledge City Programme is a major endeavour entailing great challenges in the long term. For this reason, it is crucial that work on the project continue despite political change, which is assured by the total involvement not only of the state government but of the universities, the private sector and the whole community. Those behind the project believe that it will be successful thanks to the talent, entrepreneurial spirit and tenacity of the people of Nuevo Leon, and that in turn the community will be able to enjoy the benefits of all the work invested.

For further information, contact:

Reynold Gonzalez, Director, Research and Technological Innovation Park

Director, Development and Technology Transfer, Institute of Innovation and Technology Transfer of Nuevo Leon

Pablo A. Gonzalez 888, Col. Colinas de San Jeronimo

64630 Monterrey, Nuevo Leon, Mexico

E-mail: reynold.gonzalez@mtycic.org

www.mtycic.com.mx

www.piit.com. $m x$

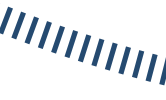

IIIIIIII)

\section{THE HIGHER EDUCATION LEARNING ENVIRONMENT: A FINNISH TECHNOLOGY HUB}

\author{
By Nils Gersberg and Suvi Nenonen, Helsinki University of Technology, Finland
}

This article describes several aspects of the higher education learning environment and ways to organise the university campus to support different kinds of learning processes. The pedagogical paradigm is changing, with greater focus on students' search for knowledge through dialogues with each other and their teachers. Extending the traditional one-way communication of wisdom from teacher to student requires changes to university premises. In this article, a set of design criteria is applied to the campus area in the Finnish technology hub of Otaniemi, to demonstrate the variety of properties required for modern learning environments.

\section{Learning environment}

The learning environment should be composed of physical and virtual environments, as well as a social environment, facilitating both interaction and individual privacy in learning processes.

\section{Physical learning environment}

Physical places are needed for learning, discussion and group work. Spaces for group work should be of different sizes, from auditoriums to small nooks. The cafeteria can be a flexible space used for group work or as an all-day cafe. 


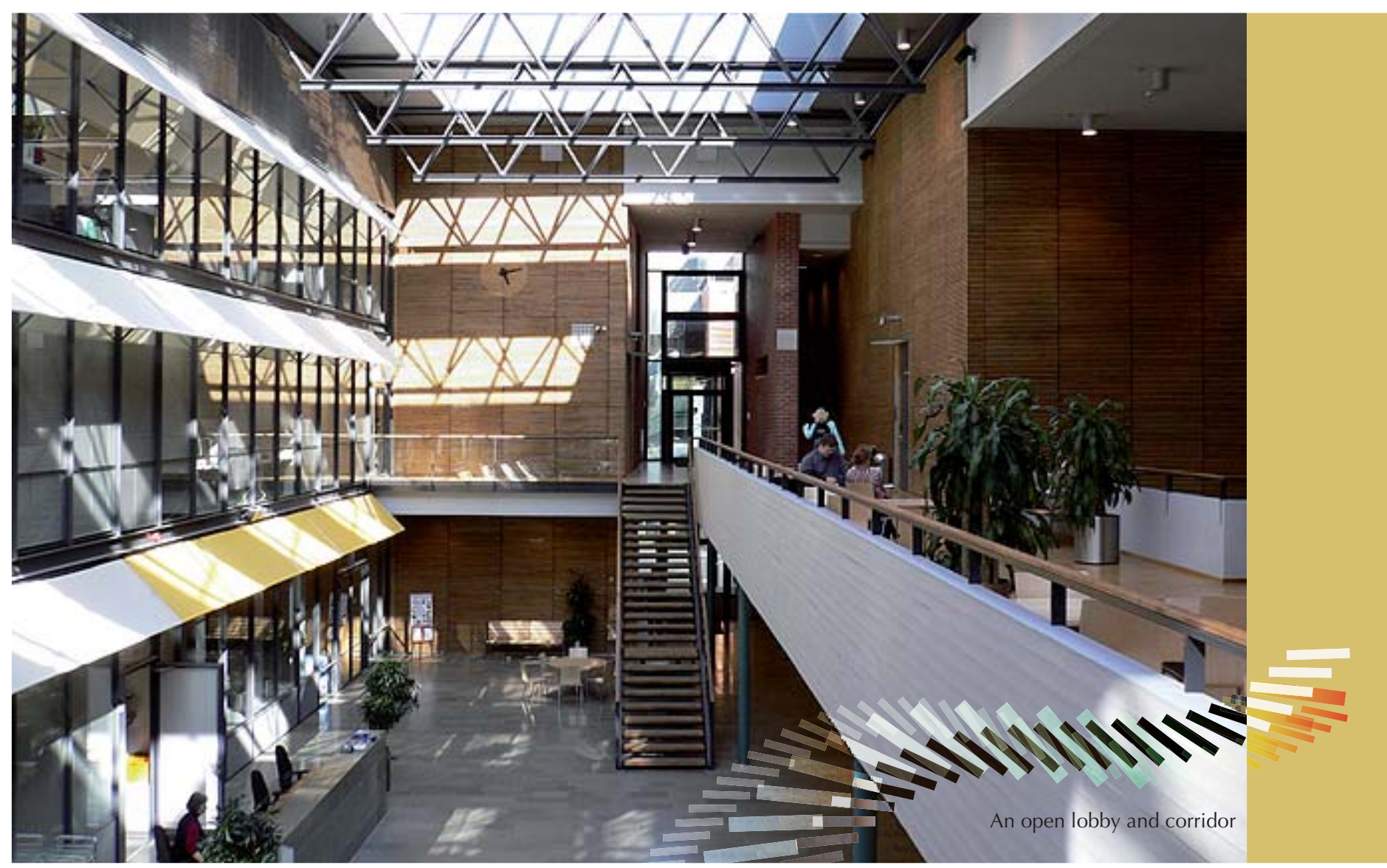

A physical learning environment is needed to obtain information and to study. The library, as the knowledge hub of the university, should be centrally located for information gathering, with many terminals, multimedia workstations and connections to foreign information networks.

Teachers' workspaces should not be isolated in a separate administration wing but located in the middle of the learning spaces or in their immediate vicinity. While participating in learning situations, teachers themselves also learn, experiment and observe. Several teachers may be present in the same learning situation. Workplace solutions like combi-offices with shared workstations and separate rooms for concentrating can be relevant for the progressive educational environment.

The spaces should be furnished with comfortable and pleasant furniture that enables versatile use. Traditional furniture for schools has consisted of a desk and chair. However, this concept is poorly suited for the modern way of working at school. Office-type furniture with tables that can be grouped in various ways is better suited. Informal work environments increase the sharing of tacit knowledge. The learning space may also resemble a living room, with rocking chairs, couches and plants. The whole of the building technology - lighting, air conditioning and waste management - should provide a positive example of an environment based on sustainable development.

\section{Virtual learning environment}

Educational institutions can create virtual learning communities by using information and communications technology. The virtual environment can break physical borders, widening social networks and allowing greater interactivity and rewarding experiences. Many emerging technologies can emulate most traditional classroom equipment and enrich learning. 
In terms of academic results, virtual learning environments have proven to be motivating contexts for learning and can be more successful than traditional ones. They are more flexible, more accessible and more inclusive. Not only are these environments often a more economically viable option, but they also allow specialist knowledge to cross geographical boundaries.

However, one of the main disadvantages of the virtual learning environment is the lack of face-to-face interaction and direct social contact among the students and teachers which conventional educational contexts provide. It is because of these factors, and the lack of evidence of how they will impact on students' personal and social development, that virtual learning environment may not entirely replace traditional classrooms and teacher-student contacts.

From a technical perspective, installing technology systems has often resulted in a disordered bundle of cords. One solution is to adopt the floor structure commonly used in office buildings: on top of the suspended slab is a separate light installation floor under which all the electric networks and cords run.

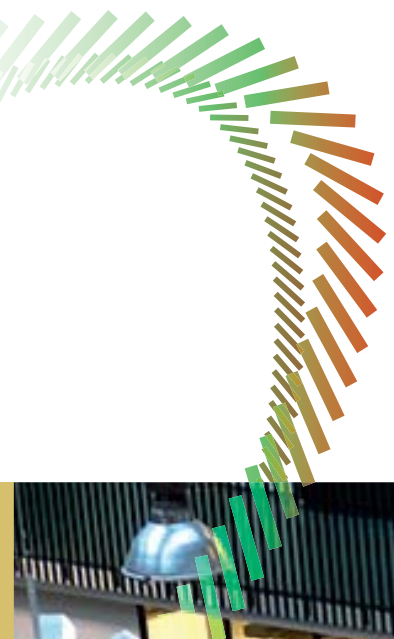

\section{Social learning environment}

The social learning environment provides students places to meet, to associate with each other and to experience things together. The academic community is a complex network of human relations, work plans, schedules and daily activities, for which the building constitutes a physical

A dining area, lockers and computer rooms

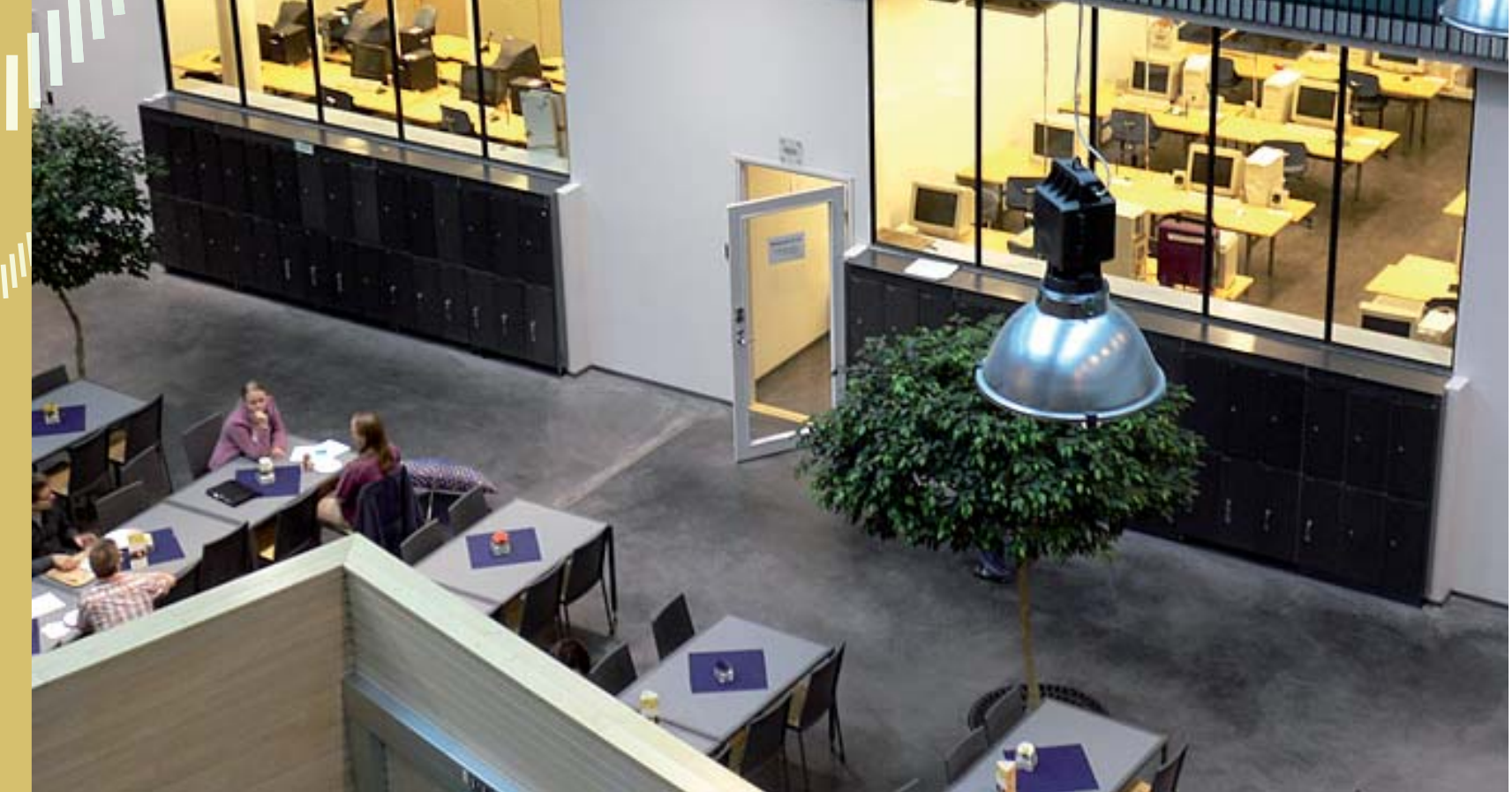




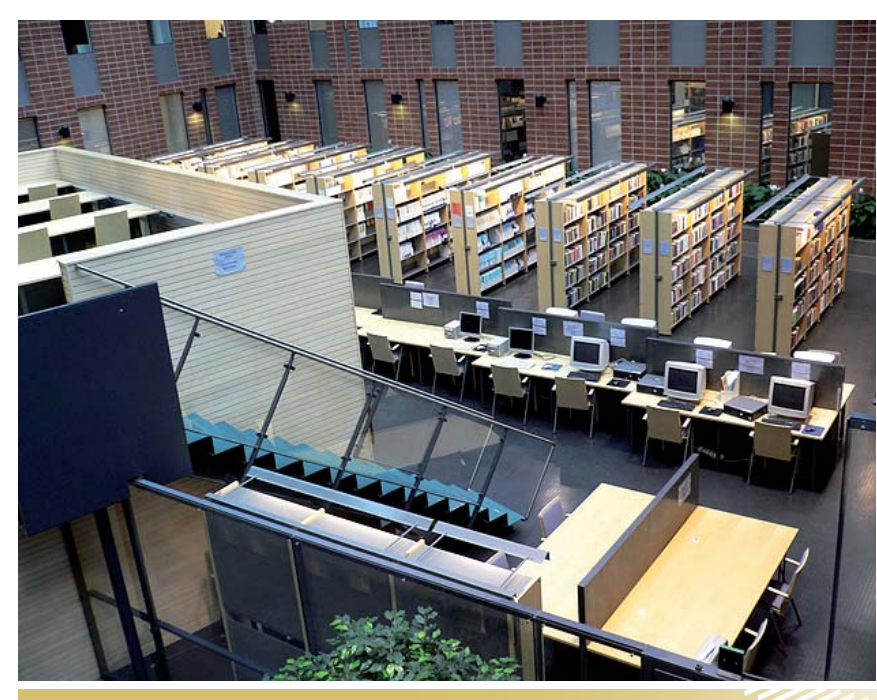

The library of the Helsinki University of Technology

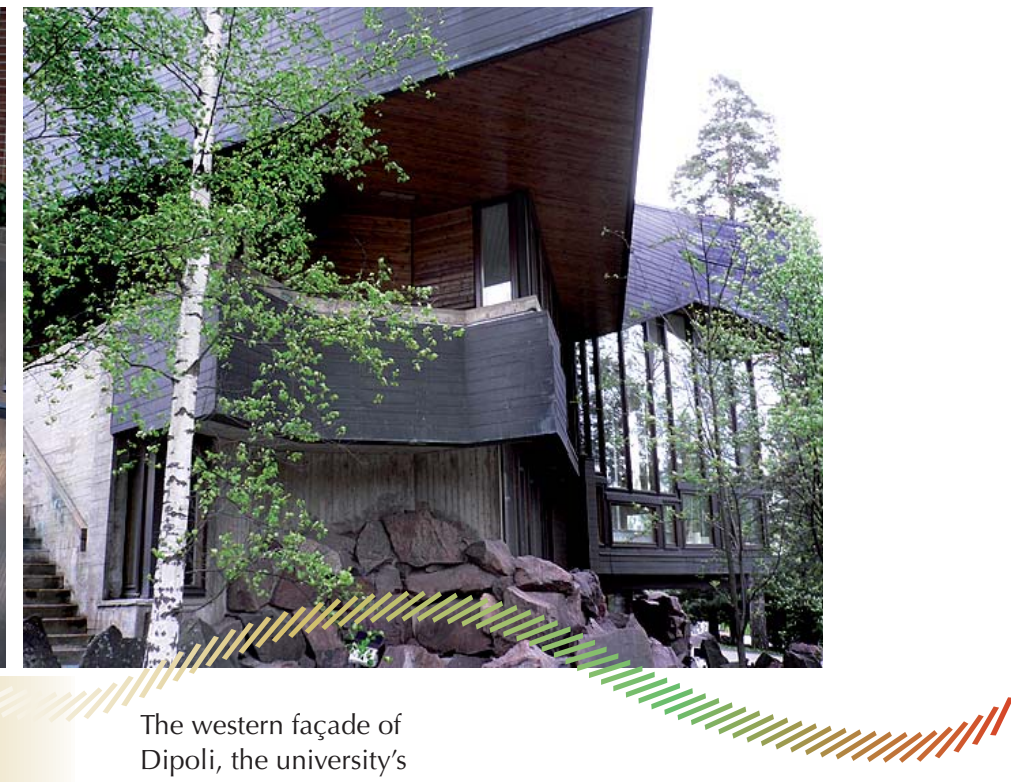

Lifelong Learning Institute

environment with its own material flows and internal requirements. The educational building itself can direct and determine behaviour within the environment - it places restrictions on the core activities as well as offering opportunities to support them.

Social development, the buildup of professional networks, essentially all activities which increase social capital or trust, often rely on direct face-to-face communication. To what extent the maturing virtual learning environment will be able to replace these direct contacts remains to be seen.

\section{Otaniemi case study}

Since Finland has successfully used a classification scheme for buildings in the basic education sector, an interesting exercise is to test that scheme on buildings for higher education. This case study applies the scheme's eight criteria to the campus environment of Otaniemi.

Otaniemi, a neighbourhood of Espoo, has grown around the Helsinki University of Technology and VTT Technical Research Centre of Finland to become the heart of Finnish science and technology and the leading technology hub in the Nordic countries. Otaniemi is a prime example of how physical proximity and interconnectedness foster collaboration and innovation between organisations. An increasing number of large companies and research organisations, both Finnish and international, are setting up business there. These companies value the area's solid infrastructure, its innovative and entrepreneurial spirit, and the availability of a wide base of potential new employees. The Otaniemi model, which emphasises diversity and collaboration, has inspired numerous technology centres both in Finland and abroad.

The area is architecturally unique, boasting buildings designed by leading architects including Alvar Aalto.

The campus area of the Helsinki University of Technology and VTT Technical Research Centre of Finland has an interesting history: For the 1952 Olympic Games in Helsinki the athletes were housed in newly constructed buildings in Otaniemi; new additions were made more recently in order to host the 2005 World Championships in Athletics. These houses were later turned into student apartments. Today the village houses 3000 students, a substantial part of the student population. 
The focal point of the Helsinki University of Technology is the auditorium building with two large halls at the campus centre (intended for international conferences in addition to university events). All classrooms are in adjacent buildings grouped around small internal courtyards, where are also found small lecture rooms, laboratories and professors' rooms. The chief materials are dark red brick, black granite and copper.

The library closes off at an oblique angle the third side of the park/court created by the main classroom buildings. As a major reference library, the main problem was to provide good working conditions for the students among the library stacks stored in a three-storey basement. These spaces and the small lending collection are housed in a faceted volume on the side, away from the main buildings. In the rectilinear tail of the building, offices and seminar rooms are provided.

Closeness to nature has been well preserved in Otaniemi, partly due to protected areas. The coastlines, in particular, have not been touched.

\section{Table 2. Criteria applied to the higher education campus area in Otaniemi}

Criteria for school buildings

Offers a flexible environment
Examples at Otaniemi campus area

Campus location

University buildings, research centre buildings, incubator buildings, library and facilities

Variety in use: from individual space to collaborative space

Encourages learning

High-tech solutions in older and modern parts of campus area
Wireless connections

Green values in facilities services

Goals of social responsibility

Old and new workplace solutions

Unique setting for education, research and practice

\section{Has a multidimensional centre for multiple usage}

Is challenging

Supports interaction

Location in a region which values innovation

Library and main building located at the centre of the campus

Variety of cafeterias and options for lunch

Places for informal gatherings

Provides schooling for everyone

Education, research and trainee premises; student housing in the campus area Accessibility, inclusive design, design for all

Is aesthetic

Architecture by Alvar Aalto

Use of local materials

Close connection with nature

Supports identity
Campus identity

Student identity, researcher identity

Business incubator settings providing entrepreneurship 


\section{Conclusions}

New ways to learn and work require new kinds of environments, for individual and collaborative learning and work as well as for formal and informal activities.

An innovative region can be developed by combining different sectors of society: education, research and practice. Collaboration of this sort adds value for all partners, and the campus does not become an enclave for university education and research but a think tank for business, innovation and lifelong learning.

For further information, contact:

Nils Gersberg

CEM Facility Services Research

Helsinki University of Technology

P.O. Box 9800, FIN-02015 TKK

Finland

E-mail: nils.gersberg@tkk.fi

Suvi Nenonen

CEM Facility Services Research

Helsinki University of Technology

E-mail: suvi.nenonen@tkk.fi

\section{UNIVERSITY OF SALAMANCA'S R\&D\&I BUILDING}

By Pablo Campos Calvo-Sotelo, University Campus Planning and Design, Spain

The future Research, Development and Innovation (R\&D\&I) Building, at the University of Salamanca, Spain, was designed to integrate a range of complex scientific and technological facilities within a single architectural shell.

The R\&D\&I Building will be one of five buildings to make up the Science Park on the Villamayor campus (see PEB Exchange no. 56, October 2005). Work on the site, measuring $23158 \mathrm{~m}^{2}$, began in December 2006.

\section{Architectural project}

The main challenge in designing the R\&D\&I Building was housing several different advanced and expensive research facilities together:

Petawatt laser: This important piece of equipment (one of the ten most powerful in the world) necessitates a translucent, vibration-free $50 \times 12$ metre space, totally insulated from the outside, because of radiation emissions.

Low temperature laboratory: The core element is a slim vertical electromagnet $2.5 \mathrm{~m}$ high. Its power output is so high (20 teslas) that any steel construction within a $12 \mathrm{~m}$ circumference would be damaged. A non-ferromagnetic steel is needed to enclose that space.

DNA data bank and cytometry: The laboratories and other areas of these facilities require careful planning to provide adequate insulation and structural strength for heavy equipment. 


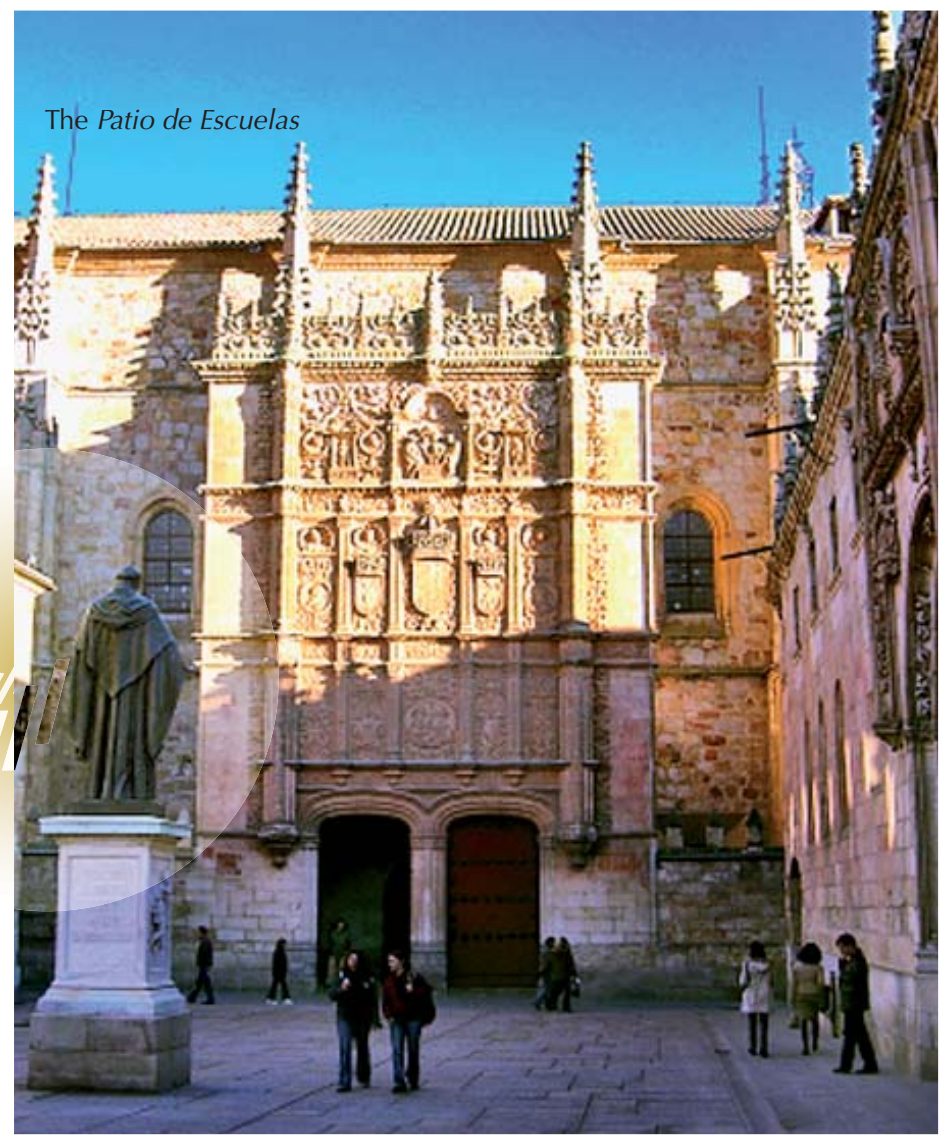

The composition is inspired by local planning and architectural types: the plaza formed by the roof of the ground floor evokes the campus' traditional Patio de Escuelas, and the proportions of the central body's northern volume hint at the façade of the University's Escuelas Mayores, designed in 1529.

\section{Spatial approach}

The entrance to the complex is via a double staircase: the section outside the building leads to the raised panoramic plaza, while the interior section starts from the entrance hall. The two sections coincide, with the peculiarity that they are separated only by a thin glass membrane.

Inside, the ground floor offers a large central space, translucent and hermetically sealed, which houses the petawatt laser. The low temperature laboratory is located in the southeast corner, relegated to a peripheral sector because of its strict structural requirements.

The DNA data bank and cytometry cover the first and second floors in the eastern section houses. Their layout follows a comb-like pattern, with linear passageways (corridors and staircases) parallel to the curtain wall.

\section{Materials}

The R\&D\&I Building is striking for the simplicity of its exposed materials, which provide a clear view of the building's architectural composition. The materials - dark-coloured granite, aluminium sheets, glass panels and wood - were chosen not only to provide a technical solution to the project, but also to establish links with the local building tradition. Light interiors predominate, compatible with the uses of the facilities. 
The building incorporates solar panels for supplementing the main energy source.

The R\&D\&I Building was commissioned by the University of Salamanca (under the supervision of E. Battaner, Rector, P. Eslava, Vice Rector, and M. Gonzalez, Director), the Government of Castilla and Leon, and the Ministry of Education. It was designed by Pablo Campos in collaboration with ProintecAngel Cordero. The building is expected to be complete and ready for use for the 2008/09 school year.

For further information, contact:

Pablo Campos Calvo-Sotelo, PhD Architect

University Campus Planning and Design

Spain

E-mail: utoplan@telefonica.net

www.utoplan.com 


\section{ORGANISATION FOR ECONOMIC CO-OPERATION AND DEVELOPMENT}

The OECD is a unique forum where the governments of 30 democracies work together to address the economic, social and environmental challenges of globalisation. The OECD is also at the forefront of efforts to understand and to help governments respond to new developments and concerns, such as corporate governance, the information economy and the challenges of an ageing population. The Organisation provides a setting where governments can compare policy experiences, seek answers to common problems, identify good practice and work to co-ordinate domestic and international policies.

The OECD member countries are: Australia, Austria, Belgium, Canada, the Czech Republic, Denmark, Finland, France, Germany, Greece, Hungary, Iceland, Ireland, Italy, Japan, Korea, Luxembourg, Mexico, the Netherlands, New Zealand, Norway, Poland, Portugal, the Slovak Republic, Spain, Sweden, Switzerland, Turkey, the United Kingdom and the United States. The Commission of the European Communities takes part in the work of the OECD.

OECD Publishing disseminates widely the results of the Organisation's statistics gathering and research on economic, social and environmental issues, as well as the conventions, guidelines and standards agreed by its members.

This work is published on the responsibility of the Secretary-General of the OECD. The opinions expressed and arguments employed herein do not necessarily reflect the official views of the Organisation or of the governments of its member countries.

No reproduction, copy, transmission or translation of this publication may be made without written permission. Applications should be sent to OECD Publishing rights@oecd.org or by fax 331452499 30. Permission to photocopy a portion of this work should be addressed to the Centre français d'exploitation du droit de copie (CFC), 20, rue des Grands-Augustins, 75006 Paris, France, fax 331463467 19, contact@cfcopies.com or (for US only) to Copyright Clearance Center (CCC), 222 Rosewood Drive Danvers, MA 01923, USA, fax 1978646 8600, info@copyright.com. 